\title{
O PRECEDENTE JUDICIAL NO ORDENAMENTO JURÍDICO
}

\section{BRASILEIRO}

\section{THE JUDICIAL PRECEDENT IN THE BRAZILIAN LEGAL SYSTEM}

\author{
${ }^{1}$ Nayara Maria Silvério da Costa Dallefi \\ ${ }^{2}$ Ana Cristina Lemos Roque
}

\section{RESUMO}

Os ordenamentos jurídicos decorrentes do sistema da civil law, utiliza-se a lei como fonte primária do direito, pautados no positivismo jurídico, inclusive o ordenamento jurídico brasileiro, com tradição que remonta desde a antiguidade e com forte influência do direito francês. Em contrapartida, o sistema da common law, também conhecido como sistema inglês, para designar direito comum na Inglaterra, em virtude dos costumes locais, é um judge-madelaw. Partindo uma pesquisa histórico-bibliográfica, o presente artigo visa apresentar os dois sistemas acima e a questão do precedente judicial no ordenamento jurídico brasileiro para o fim demonstrar a distinção entre os dois sistemas.

PALAVRAS-CHAVES: Precedente Judicial. Ordenamento Jurídico Brasileiro. Common Law. Civil Law

\section{ABSTRACT}

The legal systems deriving from the civil law system, law is used as the primary source of law, based on legal positivism, including the Brazilian legal system, with a tradition dating back to antiquity and with strong influence of French law. In contrast, the common law system, also known as the English system, to designate common law in England, by virtue of local customs, is a judge-made-law. Based on a historical-bibliographic research, the present article aims to present the two systems above and the question of judicial precedent in the Brazilian legal system for the purpose of demonstrating the distinction between the two systems.

KEYWORDS: Judicial Precedent. Brazilian Legal Order. Common Law. Civil Law

\footnotetext{
${ }^{1}$ Doutoranda em Direito Previdenciário na Pontifícia Universidade Católica - PUC-SP, São Paulo, SP. (Brasil). Mestre em Direito, no Programa de Estudo Pós Graduado em Direito, do Centro Universitário Eurípedes de Marília - UNIVEM, São Paulo, SP, (Brasil). Pós-graduada na área do Direito pela Universidade Estadual de Londrina-UEL. Paraná, PR, (Brasil). Bacharel em Direito pelas Faculdades Integradas Antônio Eufrásio de Toledo, em Presidente Prudente-SP, São Paulo, Sp, (Brasil). Atualmente é advogada militante e professora universitária na FAPEPE de Presidente Prudente, São Paulo,Sp, (Brasil). Professora de Pós Graduação da Infoc Instituto Nacional de Formação Continuada. Tem experiência na área do Direito, com ênfase em Direito Civil, Direito Previdenciário e Processual Civil. Coordenadora da Comissão da Assistência Judiciária de Presidente Prudente-SP ( $3^{\circ}$ mandato), Membra da Comissão da Mulher Advogada e do Jovem Advogado, também na cidade de Presidente Prudente, São Paulo, SP (Brasil). E-mail: naydallefi@hotmail.com; nayaradallefi@adv.oabsp.org.br.

${ }^{2}$ Mestranda em Teoria Geral do Direito e do Estado no "Centro Universitário Eurípedes de Marília - UNIVEM, São Paulo, SP, (Brasil). Bolsista Capes/Prosup. Especialista na área de concentração Direito Empresarial e Tributário pelo Centro Universitário Rio Preto - UNIRP, São APulo, Sp, (Brasil). - Advogada e Professora na Comarca de São José do Rio Preto, SP, (Brasil). Atua nas áreas de Penal e Constitucional. E-mail: anacristinalemos@bol.com.br.
} 


\section{INTRODUÇÃO}

No ordenamento jurídico brasileiro sempre se afirmou que a lei é fonte primária do direito, com fundamento do positivismo jurídico. Assim, construiu-se um sistema jurídico todo escrito, conhecido como civil law, tendo ligação com o direito da antiga Roma.

A tradição remonta à data de 450 A.C., que seria a suposta data de publicação da Lei das XII Tábuas ${ }^{3}$. Em 533 D.C. houve a publicação em Constantinopla do Corpus Juris Civilis de Justiniano ${ }^{4}$.

Já as leis bárbaras foram redigidas a partir do séc. V para a maior parte das tribos germânicas. Do ponto de vista científico, data do século XIII a formação de um sistema propriamente dito, com o Renascimento, e o estudo e sistematização nas Universidades, com glosadores e comentadores.

O civil Law é adotado ainda, na Itália, na França, na Alemanha, na Espanha e em Portugal, assim como em toda América Latina colonizada por portugueses e espanhóis. A influência de tais doutrinas é facilmente perceptível no Brasil, onde há muita influência, por exemplo, da doutrina italiana de Liebman, Chiovenda e Carnelutti, principalmente em nossa teoria geral do processo.

A formação e o desenvolvimento da doutrina do civil Law foi fortemente marcada pelo contexto histórico da França e a revolução que se seguiu, derivando daí os dogmas da

\footnotetext{
${ }^{3}$ A primeira dessas leis escritas foi a Lei das XII Tàbuas - Lex duodecim tabutarum, de 450 A.C. - portanto, escrita na metade dos primeiro século do governo republicano. A história da Lei das XII Tábuas é significativa não só pelo seu caráter inovador de ter sido escrita conjuntamente por patrícios (classe alta romana) e plebeus (classe baixa), como principalmente, por ter sido escrita. Foi em meio as transformações aspirações políticas dos plebeus que nasceu a Lei da XII Tábuas. Por volta de 450 A.C., dez homens da classe dos patrícios foram apontados para criar um Código de Leis escritas do povo romano. (...) Primeiro, foram criadas as dez tábuas. Como o trabalho foi dado como incompleto, e, como tinha sido efetuado apenas por patrícios, outros dez homens foram escolhidos para adicionar duas tábuas. Alguns desses homens eram plebeus e conseguiram introduzir nessas duas últimas tábuas alguns princípios de direito que vieram, ainda, que de forma limitada, a diminuir as diferenças que existiam entre as classes. (VIEIRA, 2007 p. 29).
}

${ }^{4}$ O Corpus Iuris Civilis foi criação do imperador Justiniano, no século VI da nossa era. Justiniano, então imperador do Império Bizantino, estabeleceu uma comissão para codificar as leis do império - que seriam chamadas de Codex. As leis deveriam ser separadas por tópicos, em títulos, e organizadas em ordem cronológica. O Codex foi publicado em 7 de abril de 529 A.D., mas não ficou muito tempo em virgor. Foi substituído em 29 de dezembro de 534 A.D. por outro Codex - que constitui o primeiro dos quatro elementos do chamado Corpus Iuris Civillis (VIEIRA, 2007 p. 29). 
supremacia da lei; da estrita separação dos poderes e do juiz como a "boca da Lei"5.Por outro lado, tem-se outro sistema diverso do acima que dá-se o nome de common law, sendo o sistema jurídico que foi elaborado na Inglaterra a partir do século XII pelas decisões das jurisdições reais. Manteve e se desenvolveu até nossos dias, também presente em países de língua inglesa a exemplo, Estados Unidos, Canadá e Austrália.

Referida expressão é utilizada desde o século XIII, para designar direito comum na Inglaterra, em virtude dos costumes locais, também conhecido como comune ley (lei comum). O common law é um judge-made-law ("o juiz faz a lei”), enquanto a jurisprudência apenas desempenhou um papel secundário na formação e evolução dos direitos romanistas.

O common law é um direito judiciário, enquanto o processo é só acessório nas concepções fundamentais dos direitos romanistas; o common law não sofreu muita influência do direito romano, diferente da civil law que sofreram uma influência do direito erudito elaborado na Idade média e, por fim, os direitos romanistas são codificados, enquanto é quase desconhecida na common law.

As revoluções americana e francesa, bem como as revoluções de independência na America Latina influenciaram especialmente o direito público de tradição romano-germânica. Desta feita, diante uma pesquisa histórico-bibliográfica, o presente artigo visa apresentar os dois sistemas acima e a questão do precedente judicial no ordenamento jurídico brasileiro.

Isto porque, as revoluções mencionadas eventos consistiram numa verdadeira revolução intelectual com novos pensamentos sobre a humanidade, sociedade, economia e Estado. Essa revolução intelectual não influenciou apenas o direito publico, mas também a forma de administração e organização do sistema jurídico e algumas regras substantivas e de direito processual.

\footnotetext{
${ }^{5}$ Antes da Revolução Francesa, os membros do judiciário francês constituíam a classe aristocrata não apenas sem qualquer compromisso com os valores da igualdade, da fraternidade e da liberdade - mantinham laços visíveis e espúrios com outras classes privilegiadas, especialmente com a aristocracia feudal, em cujo nome atuavam sob as togas. Nesta época, os cargos judiciais eram comprados e herdados, o que fazia supor que o cargo de magistrado deveria ser usufruído como uma propriedade particular, capaz de render frutos pessoais. Os juízes pré-revolucionários se negavam a aplicar a legislação que era contrária aos interesses dos seus protegidos e interpretavam as novas leis de modo a manter o status quo e a não permitir que as intenções progressitas dos seus elaboradores fossem atingidas. Não haveria qualquer isenção para "julgar". A preocupação em desenvolver um novo direito e permitir o desbrochar de uma nova sociedade exigiu a admissão de argumentos de Montesquieu, aceitando-se a necessidade da separação dos poderes impondo-se, sobretudo, uma clara distinção entre as funções do legislativo e do judiciário. Tornou-se imprescindível limitar a atividade do judiciário, subordinando-o de forma rígida ao Parlamento, cujo habitantes deveriam representar os anseios do povo. De acordo com Montesquieu, o "poder de julgar" deveria ser exercido através de uma atividade puramente intelectual, cognitiva, não produtiva de "direitos novos". Essa atividade não seria limitada apenas pela legislação, mas também pela atividade executiva, que teria o poder de executar as decisões que o constituem o "poder de julgar". (MARINONI, 2013, p. 50 e 51).
} 
Certamente foi nos países de origem anglo-saxônica que mais se desenvolveu a teoria dos precedentes judiciais, contudo, o precedente é uma realidade inerente a qualquer sistema jurídico, seja da civil law ou da common law, como Estados Unidos e Inglaterra, variando, somente, o grau de eficácia que possui.

Nesse contexto pode-se dizer que, a principal distinção entre os dois sistemas é que o da civil law é um direito escrito, onde a jurisdição é estruturada preponderantemente com a finalidade de atuação do direito objetivo.

Enquanto no sistema da common law adota-se um direito costumeiro, aplicado pela jurisprudência, onde, no modelo de justiça, prepondera a visão de pacificação dos litigantes.

No civil law busca-se a segurança jurídica, enquanto no common law o objetivo principal é a paz entre os litigantes, a composição do litígio em questão e a reconciliação, pois o importante é harmonizar os litigantes, desde que seja adequado ao caso concreto.

Ao longo da história, no entanto, diversos fatores foram proporcionando a aproximação entre os dois sistemas, podemos destacar dentre outros: o constitucionalismo, o estado social, os conceitos indeterminados, as cláusulas gerais, as regras de textura aberta e as demandas em massa.

Num amplo contexto serão revistas algumas premissas do estudo do precedente como fonte do direito, a sua eficácia e segurança jurídica, e principalmente, não poderia deixar de abordar aqui como o presente tema pretende ser tratado no Novo CPC.

\section{BREVE HISTÓRICO}

A origem do common law remonta à conquista normanda da Inglaterra no ano de 1066, com a batalha de Hastings, que levou a centralização do governo, incluindo a administração da justiça.

Nesse período, surge o feudalismo na Inglaterra e desaparece a época tribal. A história do direito na Inglaterra assemelha-se à dos países do continente até aos séculos XII e XIII. Indo um pouco mais na origem, a Inglaterra fez parte do Império Romano, do século I ao V, sendo que a colonização romana foi pouco extensa, a exemplo do Norte da Gália.

Com as invasões dos povos Anglo-saxões, e Dinamarqueses, desenvolveu-se aí reinos germânicos à partir do sec. VI, com leis bárbaras, ou seja, textos do direito consuetudinário anglo-saxônico, assim, enquanto as leis do continente são redigidas em latim, as da Inglaterra passam a serem redigidas em língua germânica. 
O Direito Inglês teve uma continuidade histórica sendo fruto de uma longa evolução, sem grandes rupturas na ordem jurídica havendo um gradual desenvolvimento do common law.

O direito passa a se desenvolver na Inglaterra com base na lista de writs - ações judiciais sob forma de ordens do rei. Na hipótese de litígio, era essencial buscar os writs ao caso concreto, sendo que o processo é mais importante do que as regras do direito positivo. $\mathrm{O}$ common law foi elaborado assim com base em um número limitado de formas processuais.

Assim aos poucos foi sendo formadas a organização e a competência dos tribunais no sistema Inglês. O common law passou a ter regras procedimentais, rígidas, bem como remédios preestebelecidos, sendo que aqueles que não aceitavam as decisões podiam peticionar para o Rei, pedindo-lhe uma reconsideração, uma espécie de perdão.

A história do direito inglês irá nos revelar o fato de ser um direito de criação por seus julgadores, sendo mesmo anterior a invasão normanda, até o advento da Judicature Act, em 1873, quando se deu a fusão das jurisdições, da commow law, desenvolvida ao longo de mais de oito séculos, e da equity, que surgiu como um recurso contra decisões flagrantemente injustas em casos concretos, transferindo ao soberano ou chanceler que em seu nome falava o poder de rever a sentença proferida segundo o direito comum.

Após 1875, com o Judicature acts, os tribunais superiores passam a poder pronunciarse validamente tanto sobre o Direito como sobre a equidade, pois o Commom Law e a Equity seriam admitidas simultaneamente e concorrentemente pelas mesmas jurisdições.

O common law torna-se dessa forma cada vez mais técnico nestes séculos, limitado no processo dos writs pela rotina dos juízes, sendo que estes, embora nomeados pelo rei, tornaramse independentes - o Chanceler decidia em equidade sem ter em, conta regras do processo ou até mesmo o uso do common law, julgando segundo princípios muitas vezes extraídos do direito romano, entretanto, do direito romano restou poucas influências ${ }^{6}$.

Insta salientar que o direito inglês moderno, diversamente do civil law, é muito mais um direito histórico, sem rupturas entre o passado e o presente como aconteceu nos direitos de

\footnotetext{
${ }^{6} \mathrm{O}$ common law acabou tendo um papel primordial no direito inglês, servindo o statute law apenas para promover adequações do common law. Hoje, a realidade é outra, sendo muito mais comum a atividade do Parlamento. O common law no sentido lato, por sua vez, se subdvide em common law e equity. A equity foi importante na formação do direito inglês, especialmente para estabelecer princípios gerais do direito, além de promover a justiça e os anseios da sociedade. Já o common law se desenvolveu com base nas decisões judiciais, com pouco ou quase nenhuma influência do direito romano, podendo se apresentar as seguintes distinções do civil law: i) é um direito histórico, sem rupturas; ii) é um judge-made-law, em que a jurisprudência exerce papel de grande importância no sistema jurídico; iii) é um direito judiciário; iv) é um direito não codificado; (...) Diferentemente do civil law, no qual a autoridade da lei está na autoridade de quem a promulgou, no common law a autoridade do direito está em suas origens e em sua geral aceitabilidade por sucessivas gerações. (BARBOZA, Estefânia Maria de Queiroz. Precedentes Judiciais e Segurança Jurídica - Fundamentos e Possibilidades para Jurisdição Constitucional Brasileira. São Paulo: Saraiva, 2014, p. 44).
} 
tradição civil law da Europa Continental, principalmente na França que rompe com o Direito preexistente com a Revolução Francesa.

No civil Law a autoridade da lei está na autoridade de quem a promulgou, no common Law a autoridade do direito está em suas origens e em sua aceitabilidade por sucessivas gerações. Admitindo-se dessa forma a autoridade do direito construído através da jurisprudência.

Para os práticos os precedentes judiciais são de uma grande utilidade o fato de poder lembrar o tribunal que já decidiu em tal sentido. A jurisprudência passa a ter dessa forma, "um papel determinante tanto em sua origem quanto em sua evolução",7.

Não houve assim, no direito Inglês nenhuma grande reforma com o estabelecimento de uma codificação geral, sendo que a legislação sempre teve um papel complementar ao direito, em respeito às fontes judiciárias, sendo que em caso de conflito, as decisões judiciais deveriam prevalecer sobre a lei, tendo em vista sua especialidade.

Apesar da importância crescente da legislação, a Inglaterra permanece um país sem constituição escrita e sem códigos. O constitucional Law inglês baseia-se no costume e nos precedentes, invoca a carta Mana de 1215 e outros Acts mais ou menos antigos.

Entretanto, não existe um conjunto de regras constitucionais reunidos, o que o difere do sistema Americano, assim como não existe nenhum conjunto de regras jurídicas relativas a um ramo do direito, como no caso do código Francês, Alemão, etc.

Os Estados Unidos da América possui grande influência da Inglaterra na formação do seu direito, tendo em vista a colonização, em parte, dos Estados Unidos pelos Ingleses. Em sua formação os Estados Unidos não adotou a idéia de supremacia do Parlamento.

A autoridade suprema não estaria no Parlamento, mas na Constituição, esta é que vai representar a vontade soberana do povo, diversamente das leis que estabelecem a vontade de seus representantes, prevalecendo uma teoria de governo limitado.

\footnotetext{
${ }^{7}$ A jurisprudência tem, desse modo, papel determinante tanto em sua origem quanto em sua evolução. Criscuoli afirma que nos quatro grandes períodos históricos do direito inglês, a jurisprudência teve importante função: i) no período anglo-saxão, anterior a conquista normanda, garantiu-se o respeito aos costumes locais; ii) no segundo período, que vai de 1066 até 1485, com surgimento da Dinastia dos Tudors, trabalhou-se na elaboração jurisprudencial dos costumes locais e de outras fontes menores do direito, desenvolvendo-se nessa época o common law; iii) durante o terceiro período, que vai da segunda metade do século XV até 1875 , consolidou o common law paralelo ao equity; iv) por fim, no quarto período, que vai das últimas décadas do século XIX até os dias de hoje, a atividade judiciária passa a lidar com um maior número de leis, cem como com as normas supranacionais da Comunidade Europeia. (BARBOZA, Estefânia Maria de Queiroz. Precedentes Judiciais e Segurança Jurídica - Fundamentos e Possibilidades para Jurisdição Constitucional Brasileira. São Paulo: Saraiva, 2014, p. 44)
} 
Um dos alicerces centrais do common law nos Estados Unidos foi a doutrina de respeito ao precedente judicial e a doutrina dos direitos humanos fundamentais, no entanto, é apenas no século XVII é que o common law nos Estados Unidos evoluiu, acompanhando transformações na economia e na sociedade, e passou a ser usada como um escudo contra o absolutismo real e para proteger as liberdades públicas.

Tal evolução teve o reforço da independência dos Estados Unidos no ano de 1776, seguida da promulgação da Constituição em 1787 e do Bill of Rights de 1789. Assim o Direito praticado nos Estados Unidos, se distingue do direito existente na Inglaterra, destacando a sua originalidade, muito embora lá também tenha se estabelecido a doutrina do stare decisis.

Assim diferentemente da Inglaterra, os precedentes judiciais nos Estados Unidos são menos rígidos a ponto de o seu caráter vinculante aos órgãos jurisdicionais inferiores ser menos rigoroso, permitindo dessa maneira, maior flexibilidade na adoção da doutrina do stare decisis.

\section{DO PRECEDENTE, DA JURISPRUDÊNCIA DOMINANTE E SÚMULA}

Existe na doutrina uma grande confusão entre precedente, jurisprudência, súmula e súmula vinculante. No entanto, pode-se dizer que precedente é a decisão judicial tomada à luz de um caso concreto, cuja essência pode servir como diretriz para o julgamento posterior em casos idêntico, nesse sentido, discorre BARBOSA (2014, p. 234):

\footnotetext{
(...) nos sistemas de common law a busca pela segurança jurídica não estava baseada na lei, ou na suposta completude do sistema, mas no sistema de precedentes judiciais, no qual por meio de uma racionalidade se procurava garantir a coerência entre as decisões. Assim, nesse sistema, em que pese o juiz não se encontrar limitado pela lei, se encontrava limitado pelos precedentes. Essa limitação imposta pela doutrina do stare decisis significa respeito aos precedentes; respeito este que engloba o ato de segui-los, distingui-los ou revogá-los.
}

O precedente é composto por circunstâncias de fato que embasam a controvérsia, bem como da tese ou princípio jurídico assentado na motivação do provimento decisório.

Os precedentes irão funcionar como elementos de justificação de uma decisão jurídica, e a forma como eles são enunciados pode ser decisiva para determinar sua força nos casos futuros.

O precedente se origina de um caso concreto, e para ser utilizado em outro caso concreto exigindo-se a demonstração da semelhança existente entre esse e aquele, devendo assim ser enfrentada a norma jurídica firmada no precedente, assim podemos afirmar que a 
questão do caso é mais complexa do que a questão jurídica, tornando-se imprescindível ter uma idéia clara dos fatos do caso.

Nesse sentido, assevera Karl Larenz (1997, p.611) :

Os precedentes são resoluções em que a mesma questão jurídica, sobre a qual há que decidir novamente, foi resolvida uma vez por um tribunal noutro caso. Vale como precedente, não a resolução do caso concreto que adquiriu força jurídica, mas só a resposta dada pelo tribunal, no quadro da fundamentação da sentença, a uma questão jurídica que se põe da mesma maneira no caso a resolver agora.

A jurisprudência, por sua vez é a reiterada aplicação de uma mesma decisão, podendo virar, inclusive, uma jurisprudência dominante que, como o próprio adjetivo já informa, é a orientação que prevalece.

Nos sistemas que se baseiam tradicionalmente e tipicamente no precedente, geralmente a decisão que assume caráter de precedente pode ser apenas uma, contudo, em sistemas como o nosso, faz-se referência a varias decisões.

A súmula, no entanto, tanto pode ser formada em razão de uma jurisprudência, como também em razão do amplo reflexo de determinada matéria, ou seja, da extensão da repercussão do objeto central do provimento jurisdicional buscado naquela decisão.

Antes de adentrar ao tema propriamente dito houve um cuidado de tratar o instituto dos assentos - foram presentes no ordenamento lusitano - que antecederam a súmula no direito pátrio.

De forma sintetizada, as súmulas tiveram origem nos assentos portugueses, mas sua idealização no Brasil, atribuível ao Ministro Vitor Nunes Leal, com as denominadas súmulas persuasivas, decorre do século XX. Enfim é na virada do século XXI que mesmo sob muitas críticas, foi inserida a súmula com caráter vinculante em decorrência da reforma do Judiciário, promovida pela Emenda Constitucional de $n^{\circ} 45$, que acrescentou o art. 103-A da Constituição Federal vigente, regulamentado posteriormente pela lei $\mathrm{n}^{\mathrm{o}} 11.417$ de 2006, para disciplinar a edição, a revisão e o cancelamento de enunciado de súmula vinculante pelo Supremo Tribunal Federal (STF).

O verbete sumular vinculante é relativamente novo em nosso ordenamento jurídico. Assim os entendimentos consolidados pelo STF poderiam ser convertidos em enunciados de súmula do Tribunal, no entanto, sem efeitos obrigatórios para as demais instâncias e esferas da Administração pública. 
Nessa esteira esse intuito de uniformização da jurisprudência não é apenas lusitano. Analisando o direito comparado, vê-se exemplos dos direitos italiano e francês. No direito italiano, tem-se as Cortes de Cassação, cujas decisões possuem autoridade que está acima de todos os precedentes, em consonância com o texto legal na busca de concretização da justiça. Já no direito francês, a busca pela uniformização jurisprudencial decorre do recurso de cassação que, em prol de sua unidade, anula os julgados que vão contra a lei, sem apreciação do mérito da sentença. (STRECK, 1998, p.98).

Primordialmente a implantação da súmula vinculante traria um desafogo e facilitaria os julgamentos de milhares de processos, que eram repetição de inúmeros outros, já decididos de modo uniforme, fixando assim a jurisprudência do Tribunal, e abrindo desse modo caminho para a adoção no Brasil de uma Teoria do precedente, constituindo uma das possíveis saídas para o problema do acúmulo de processos do Poder Judiciário, e ao mesmo tempo contribuindo para a manutenção de princípios basilares da nossa Constituição, principalmente os valores de justiça e segurança ${ }^{8}$.

\section{O PRECEDENTE NO ORDENAMENTO JURÍDICO BRASILEIRO}

Hodiernamente muito se vem buscando maneiras de uniformizar a jurisprudência no Brasil. Quando o Brasil ainda era subordinado a Portugal existiam os assentos da Casa da Suplicação, Atualmente já existem em nosso CPC, vários mecanismos para fortalecimento das decisões judiciais, o que, sem dúvidas, é uma forte demonstração da influência no nosso sistema dos ditames da common Law.

\footnotetext{
${ }^{8}$ Para organização de seu programa pacificador, o Direito maneja com dois valores principais: a Justiça e a Segurança. (...) Sem a paz não se pode pensar em justiça, mesmo porque sendo absoluta e inacessível em sua totalidade, e ensejando aos indivíduos e grupos captação e entendimento por ângulos e modos distintos, a justiça, quando levada ao absoluto, tem de fomentar disputas e atritos sem fim. Em suma: enquanto a segurança conduz à paz, a justiça induz à guerra. Como valor absoluto da Justiça está fora do alcance da obra normativa do homem, o direito se contenta em implantar a ordem, a segurança, dentro de um norte inspirado em certos padrões extraídos de alguns valores éticos que o anseio de justiça da sociedade consegue ressaltar. O mundo do Direito, portanto, não é o da Justiça (em seu feitio absoluto). É o da segurança. Sem justiça alguma o Direito - é verdade - encontrará dificuldades para manter seu projeto de pacificação social. Sem segurança, porém, o Direito Simplesmente não existe. (grifei) (O Processo na Constituição - coordenadores Ives Granda da Silva Martins e Eduardo Jobim - "As reformas do Direito Processual Civil e o Princípio Constitucional da Segurança Jurídica" Humberto Theodoro Júnior, 2008, p. 262).
} 
O que se busca com a adoção de novos paradigmas é a estabilidade e a continuidade dinâmicas do direito, características típicas da common law, que assim se complementam, impulsionadas pela liberdade e pela criatividade dos juízos e tribunais inferiores.

O Novo CPC, seguindo a evolução doutrinária, busca uniformizar e estabilizar a jurisprudência, prestigiando os primados da segurança jurídica, isonomia, livre convencimento motivado e do contraditório.

O precedente nos oferece uma regra universal que será aplicada em função da identidade com os fatos análogos. O critério de aplicação e escolha do precedente é um critério fático, de modo que a regra será afastada pelo julgador conforme ele considere que prevalece os elementos de identidade ou diferença entre os casos. Nesse contexto, um só precedente é suficiente para fundamentar a decisão de um caso.

A instituição dos precedentes no projeto do Novo Código Civil é sem dúvida a mais importante inovação, com base nos princípios constitucionais da legalidade, da segurança jurídica, da duração razoável do processo e da isonomia, assim, sob esse prisma, o projeto busca trazer ao operador do direito a segurança de decisões estáveis.

Discorrendo sobre o assunto MARINONI (2013, p.120), assevera:

O Estado brasileiro, além de ter o dever de tutelar a segurança jurídica, deve realizar as suas funções de modo a prestigiá-la, estando proibido de praticar atos que a reneguem. $\mathrm{O}$ cidadão precisa ter segurança de que o Estado e os terceiros se comportarão de acordo com o direito e de que os órgãos incumbidos de aplicá-lo o farão valer quando desrespeitado. Por outro lado, a segurança jurídica também importa para que o cidadão possa definir o seu próprio comportamento e as suas ações. O primeiro aspecto demonstra que se trata de garantia em relação ao comportamento daqueles que podem contestar o direito e têm o dever de aplicá-lo; o segundo quer dizer que ela é indispensável para que o cidadão possa definir o modo de ser das suas atividades. Não obstante, para que a ideia de segurança jurídica não se perca em uma extrema generalidade, convém discriminar dois elementos imprescindíveis à sua caracterização. Para que o cidadão possa esperar um comportamento ou se postar de determinado modo, é necessário que haja univocidade na qualificação das situações jurídicas. Além disso, há que garantir-se previsibilidade em relação ás consequências das suas ações. $\mathrm{O}$ cidadão deve saber, na medida do possível, não apenas os efeitos que as ações poderão produzir, mas também como os terceiros poderão reagir diante delas. Note-se, contudo, que a previsibilidade das consequências oriundas da prática de conduta ou ato pressupõe univocidade em relação à qualificação das situações jurídicas, o que torna esses elementos indissociavelmente ligados. 
$\mathrm{O}$ precedente facilita o julgamento de demandas repetitivas e executa de forma concreta o princípio da igualdade formal entre os jurisdicionados, que ao promoverem demandas passam a contar com respostas uniformes por parte do judiciário.

Sob esse contexto, para que ocorra uma mudança do entendimento que já se encontra sedimentado deve existir uma fundamentação adequada e específica, considerando a estabilidade das relações jurídicas, afigurando-se um dever argumentativo das partes, o exercício do contraditório e da argumentação, oferecendo assim regra universal aplicada em função da identidade com os fatos dos casos análogos.

Sobre o presente tema assevera Bustamante (2012):

[...] é pela via das teorias da argumentação jurídica que o Judiciário, mesmo carente da representação democrática característica do Poder Legislativo, pode legitimar as normas jurídicas que ele deixa assentadas em suas decisões. A teoria dos precedentes, a teoria da argumentação jurídica e a teoria do Direito passam a fazer parte de um único tipo de discurso em que cada decisão concreta é considerada como uma norma universalizável que merece passar por um discurso de justificação e, num momento posterior, ser imparcialmente aplicada.

Insta salientar, no entanto, que o Novo Código de Processo Civil, tudo é jurisprudência, não se distinguindo precedente de jurisprudência, súmula, ou decisão judicial, tampouco, sobre as técnicas de superação e confronto dos precedentes, como overruling ${ }^{9}$ e distinguishing ${ }^{10}$, ou mesmo na diferenciação da ratio decidendi - razões de decidir - e da obter dicta (contribuições para chegar a fundamentação sem poder vinculatório). Tornando-se dessa

\footnotetext{
${ }^{9} \mathrm{O}$ overruling é uma espécie do gênero das denominadas judicial departures, ou seja, dos casos de afastamento de uma regra jurisprudencial. Uma hipótese de afastamento se dá quando o tribunal resolve um problema jurídico solucionável por um precedente judicial, mas de forma diferente. O juiz apela, nesses casos, para uma nova regra jurídica que conduz a um resultado diverso do previsto pelo precedente. (...) Dá-se o "afastamento" (departure) de um precedente judicial quando o tribunal posterior adota uma nova norma concreta que decide um caso compreendido na hipótese de incidência de uma regra anterior de origem jurisprudencial. Bustamente, em Teoria do Precedente Judicial (2012, p. 387)

${ }^{10}$ A técnica do distinguish é um dos elementos característicos do common law, mas tende a se expandir cada vez mais para outros domínios e tradições jurídicas. Quanto mais rígida seja a aderência do precedente judicial, mais frequente será o seu emprego. Como vimos, o distinguish pode ser descrito como uma judicial departure que se diferencia do overruling porque o afastamento do precedente não implica em seu abandono - ou seja, sua validade como norma universal não é infirmada - , mas apenas sua não- aplicação em determinado caso concreto, seja por meio da criação de uma exceção à norma adscrita estabelecida pela decisão judicial ou de uma interpretação restritiva dessa mesma norma, com o fim de excluir suas consequências para quaisquer outros fatos não expressamente compreendidos em sua hipótese de incidência. (BUSTAMENTE, 2012, p. 470).
} 
forma imprescindível o correto manejo dos instrumentos utilizados na aplicação dos precedentes.

A uniformização jurisprudencial tem como fundamento a preservação do principio da igualdade formal, pois efetiva o dever de atribuir decisões idênticas a situações idênticas. A esse respeito, conforme Luiz Guilherme Marinoni (2011, p. 01), leciona:

[...] os conceitos de coisa julgada material e de coisa julgada erga omnes não são relevantes quando se pretende dar soluções iguais a casos semelhantes. Nem mesmo a eficácia vinculante, caso limitada à parte dispositiva, ali teria alguma importância. De outra parte, falar em coisa julgada erga omnes dos fundamentos da decisão seria baralhar os institutos, já que os objetivos perseguidos com a coisa julgada e com a obrigatoriedade de respeito aos fundamentos não só não se confundem como exigem conceitos operacionais e metodologias diversos. (Elaboração dos conceitos de ratio decidendi e obter dictum presentes no direito brasileiro, cit.p.270).

Assim faz-se importante frisar que a aplicação dos precedentes em nosso ordenamento jurídico irá exigir dos juristas o aperfeiçoamento das práticas forenses e o exercício claro e cuidadoso, do contraditório e da argumentação, tornando-se, essencial que se repense toda a prática forense brasileira.

Nesse sentido SOUZA, usando palavras de SILVA, diz que "um juiz ativo é fundamental para a concretização dos direitos e garantias fundamentais." (http/www.manualdeprocessocivil.com.br/arquivos/artigo_nelson2.pdf.)

A aplicação dos precedentes no Brasil, visa desse modo, restabelecer a credibilidade do judiciário, garantindo ao litigante previsibilidade na prestação jurisdicional; o ordenamento jurídico brasileiro apresenta-se em nítida mudança, com a convergência entre o common law e o civil law, visando não só à reforma dos institutos de lei, mas também à adoção de uma teoria dos precedentes adaptada à nossa realidade, acompanhada de uma mudança de paradigma e da visão na aplicação de julgados, empregando-se coerentemente os precedentes formados. 
Uma análise aprofundada da doutrina dos precedentes, sem confundir que toda decisão judicial possa vir a ser um precedente ${ }^{11}$, irá exigir da parte dos juristas e aplicadores do direito, uma mudança de pensamento, pois um dos objetivos a serem alcançados, é que se possa, com tal prática, chegar a conclusões próprias em torno da decisão tomada.

A estrutura dos precedentes no Sistema da Common Law é pautada por princípios e regras seculares, verificados na história dos países que adotam esse sistema, sendo, nestes casos, conhecidos como os precedentes verticais, conforme aponta Tucci (2004, p.247) que, nesse sentido, assevera: "sob o aspecto temporal, uma decisão já proferida, todo precedente judicial é composto por duas partes distintas: a) as circunstâncias de fato que embasam a controvérsia; e b) a tese ou princípio jurídico assentado na motivação (ratio decidendi) do provimento decisório".

Pautar-se nas circunstâncias de fato e na motivação da decisão demonstra não só o respeito a uma decisão passada, mas também a confiança depositada por meio do Judiciário, que acarreta consequentemente, a vinculação de tais decisões aos casos futuros ${ }^{12}$, assim, concretizando a segurança jurídica das decisões judiciais.

Justamente por estes motivos é que a doutrina assevera que houve poucas modificações na doutrina dos precedentes, sendo uma delas a possibilidade de ampliar exceções no que diz respeito à rigidez da aplicação dos casos anteriores e à possibilidade de confronto com casos aparentemente idênticos

A descrição cuidadosa dos fatos e a detalhada identificação do problema a ser solucionado são apenas alguns obstáculos a serem enfrentados nessa jornada, sendo essencial a sistematização dos argumentos e opiniões, para que, dessa forma, se chegue a uma conclusão

\footnotetext{
${ }^{11}$ Seria possível pensar que toda decisão judicial é um precedente. Contudo, ambos não confundem, só havendo sentido falar em precedente quando se tem uma decisão dotada de determinadas características, basicamente a potencialidade de se firmar como paradigma para a orientação dos jurisdicionados e dos magistrados. Do modo que, se todo precedente ressair de uma decisão, nem toda decisão constitui um precedente. Note-se que o precedente constitui decisão acerca de matéria de direito - ou, nos termos do common law, de um point of law -, e não da matéria de fato, enquanto a maioria das decisões diz respeito a questões de fato. Quando são enfrentados pontos de direito, as decisões muitas vezes se limitam a anunciar o que está escrito na lei, não revelando propriamente uma solução judicial acerca da questão de direito, no sentido de solução que ao menos dê uma interpretação da norma legal. De qualquer forma, a decisão que interpreta a lei, mas segue julgado que a consolidou, apenas por isso não constitui precedente. Contudo, para constituir precedente, não basta que a decisão seja a primeira a interpretar a norma. É preciso que a decisão enfrente todos os principais argumentos relacionados à questão de direito posta na moldura do caso concreto. Até porque os contornos de um precedente podem surgir a partir da análise de vários casos, ou melhor, mediante uma construção da solução judicial da questão de direito que passa por diversos casos. (MARINONI, 2013, p. 213 e 214).

12 MARINONI, Luiz Guilherme. Precedentes Obrigatórios. $3^{\mathrm{a} e d . ~ r e v . ~ a t u a l . ~ e ~ a m p l i a d a . ~ S a ̃ o ~ P a u l o: ~ E d i t o r a ~}$ Revista dos Tribunais, 2013, p. 107.
} 
opinativa sobre o caso em questão, bem como uma argumentação aceitável sobre as razões envolvidas na decisão, pois efetiva o dever de atribuir decisões idênticas a situações idênticas.

As razões determinantes do precedente, também conhecida como ratio decidendi ${ }^{13}$ são um critério utilizado para definir o caso em questão com fundamentos necessários ao fim de proporcionar um enunciado que possa decidir o caso concreto.

A força obrigatória dos precedentes - sendo mais flexível a hipótese de mudança no direito ianque - é denominada de binding precedente; porém, mesmo diante dessa força, em julgamento pode ter resultado diverso do precedente quando utilizado o método de confronto, a partir do distinguishing ${ }^{14}$.

A justificativa para o exposto é em tese, desenvolvida para solucionar o caso concreto, busca na ratio decidendi a análise do caso concreto e a necessidade de verificar os motivos determinantes que possam se relacionar com o caso concreto atual, vislumbrando principalmente o tempo da sua aplicação; para, só assim então, pontuar se é o caso de realizar na decisão alguma distinção com o precedente apontado, sendo que o restante da decisão que levou ao precedente será tão somente obter dictum ${ }^{15}$, ou seja, a parte que fica a margem do julgamento, mas podendo ser um argumento persuasivo.

Em outras palavras, a obter dictum - dito para morrer - é todo o restante do texto que não diz a respeito à ratio decidendi, e que o Tribunal não considera essencial ao julgamento, de

\footnotetext{
${ }^{13}$ Cada precedente terá, desse modo, uma ratio decidendi. Didaticamente, com Pierluigi Chiassoni, é possível elencar sete conceitos cunhados pela tradição sobre ratio decidendi: "é o critério decisional, ou seja, a regra que está subjacente à decisão; é o princípio de direito adotado para definir o conteúdo da demanda; é a premissa ou a passagem lógica que se revela necessária para se alcançar a decisão do caso; é a regra ou princípio que constitui a condição necessária ou suficiente para definir o caso e o próprio caso, ou seja, o fato e as questões jurídicas inerentes" (STRECK, ABBOUD, 2013, p. 43).

${ }^{14}$ Esse referido processo de "distinção", dependendo das circunstâncias, implica dois tipos de atividade dos tribunais: criadora e legislativa. O tribunal pode decidir um caso de forma contrária à solução dada em um precedente, por meio de interpretação restritiva da regra extraída do precedente em cotejo com o caso sob apreciação. Descobre-se aí alguma diferença juridicamente relevante entre os elementos estruturais dos dois casos. Ao acompanhar um precedente, por outro lado, o tribunal pode afastar um ponto, entendendo que tal aparentemente exceção não encontra qualquer óbice no ordenamento jurídico. Amplia-se, destarte a regra do precedente. A despeito dessas duas formas de atividade legislativa deixadas em aberto pela eficácia vinculante do precedente, a praxe do sistema da common law produziu, ao longo do tempo, um corpo de princípios, dos quais um número significativo, quer de maior, quer de menor importância, delineia-se tão preciso como qualquer regra legislada. (TUCCI, 2004, p. 174).

${ }^{15}$ Como regra necessária à decisão, não se confunde com o obter dictum, vale dizer, passagem da motivação do julgamento que contém argumentação marginal ou simples opinião, prescindível para o deslinde da controvérsia. $\mathrm{O}$ obter dictum, assim considerado, não se presta para ser invocado como precedente vinculante em caso análogo, mas pode perfeitamente ser referido como argumento de persuasão. (IBIDEM, 2004, p. 177).
} 
modo que se for excluído da decisão em nada irá afetar suas razões decisórias. (NOGUEIRA, 2013, p.184).

Esse tipo de estrutura - da decisão que veio a se tornar um precedente - proporciona maior segurança jurídica, principalmente porque no momento em que o precedente ficar ultrapassado, no tempo e espaço a ser aplicado, ou até mesmo equivocado, utiliza-se a figura do overruling, que significa a revogação do precedente, cujo efeito é esclarecido por Tucci (2004, p.179) "o antigo paradigma hermenêutico perde todo seu valor vinculante". O overruling pode receber outras nomenclaturas como retrospective overruling, prospective overruling $\mathrm{e}$ anticipatory overruling ${ }^{16}$ a depender da situação concreta, podendo partir desde o juízo de primeiro grau, como também da Corte.

A utilização dos mecanismos dos precedentes, principalmente dos precedentes do direito norte-americanos, tornam-se necessários para uma maior efetivação diante da possibilidade de maior previsibilidade e calculabilidade e consequentemente a maior concretização do princípio da segurança jurídica.

\section{CONCLUSÃO}

Assim, sob a ótica do presente estudo apresentado a aplicação de precedentes no Brasil visa restabelecer a credibilidade do Judiciário garantindo ao litigante previsibilidade na prestação jurisdicional, nesse contexto podemos observar, que nosso ordenamento jurídico, está em nítida mudança, abandonando um pouco das premissas do sistema da civil law, e infundindo premissas da teoria do common law.

Assim, tendo-se em vista a expansão da aplicação do precedente judicial no ordenamento jurídico brasileiro, torna-se essencial a busca de instrumentos teóricos que permitam a análise e compreensão do processo de produção e apreensão do sentido das

\footnotetext{
${ }^{16}$ a) a retrospective overruling: quando a revogação opera efeito ex tunc, não permitindo que a anterior decisão, então substituída, seja invocada como paradigma em casos pretéritos, que aguardam julgamento; b) $a$ prospective overruling: instituída pela Suprema Corte Americana, na qual o precedente revogado com eficácia ex nunc, isto é, somente em relação aos casos sucessivos, significando que a ratio decidendi substituída continua a ser emblemática, como precedente vinculante, aos fatos anteriormente ocorridos; c) a antecipatory overruling: introduzida, com inescondível arrojo, pelos tribunais nos Estados Unidos. Consiste na revogação preventiva do precedente, pelas cortes inferiores, ao fundamento de que não mais constituiu good law, como já teria reconhecido pelo próprio tribunal ad quem. Basta portanto que na jurisprudência da corte superior tenha ocorrido, ainda que implicitamente, uma alteração de rumo atinente ao respectivo precedente. Ocorre aí, "uma espécie de delegação tácita de poder para proceder-se ao overruling". (IBIDEM, 2004, p. 180).
} 
decisões judiciais, pois, por meio da aplicação dos precedentes judiciais, uma decisão pode produzir efeitos em casos posteriores.

Nesse contexto será necessário repensar a prática jurisdicional brasileira, aceitando a convergência entre o Common Law e o civil Law, buscando não só a reforma dos institutos de lei, mas também a adoção de uma sólida teoria dos precedentes adaptada á realidade brasileira, acompanhada de uma mudança de paradigma e da visão na aplicação de julgados, aplicando-se coerentemente os precedentes formados, em nome do princípio da segurança jurídica.

A força e a autoridade de uma Teoria dos Precedentes estarão vinculadas, aos responsáveis por sua interpretação e aplicação; o manejo incorreto dessa teoria quebra o sistema e faz cair á pretensão de estabilidade e segurança desejada pelo judiciário, assim os operadores do direito devem estar aptos ao manuseio dos precedentes.

Tornando-se imperioso, o estudo, ainda nos bancos acadêmicos, tanto para estudantes como para juízes, o aprimoramento cultural no que se refere á aplicação dos Direitos Humanos e às demais disciplinas conexas com o caso concreto.

\section{REFERÊNCIAS BIBLIOGRÁFICAS}

ÁVILA, Humberto. Neoconstitucionalismo: entre a ciência do direito e o direito da ciência. Revista Eletrônica de Direito de Estado (REDE), Salvador, Instituto Brasileiro de Direito Público, $\quad \mathrm{n}^{\circ}$ 17, janeiro/fevereiro/março 2009, disponível na internet: $<$ http//:www.direitodoestado.com.br/rede.asp>. acesso em 26.04.2010.

Teoria dos princípios - da definição à aplicação dos princípios jurídicos. $7^{\mathrm{a}} \mathrm{Ed}$.

São Paulo: Malheiros Ed., 2007.

BARBOZA, Estefânia Maria de Queiroz. Precedentes Judiciais e Segurança Jurídica Fundamentos e Possibilidades para Jurisdição Constitucional Brasileira. São Paulo: Saraiva, 2014. 
BARROSO, Luís Roberto. Neoconstitucionalismo e constitucionalização do Direito. O triunfo tardio do Direito Constitucional no Brasil. Jus Navigandi, Teresina, ano 10, n. 851, 1 nov. 2005. Disponível em: <http://jus.uol.com.br/revista/texto/7547>;. Acesso em: 25 dez. 2010.

BUSTAMANTE, Thomas da Rosa. Teoria do Precedente: a Justificação e a Aplicação de Regras Jurisprudenciais. - São Paulo: Noeses, 2012

CÂMARA, Alexandre Freitas. Lições de Direito Processual Civil. V. I. $17^{\mathrm{a}}$ ed. inteiramente revista. Ed. Lumen Juris. Rio de Janeiro, 2008. p. 71.

CÂMARA, Alexandre Freitas, Lições de Direito Processual Civil. V. 3. $15^{\mathrm{a}}$ Ed. rev. e atualizada, Rio de Janeiro: Lumen Juris, 2008.

CARNEIRO, Athos Gusmão. Intervenção de terceiros. 19a. ed. São Paulo: Saraiva, 2010.

DIDIER JR., Fredie. Curso de Direito Processual Civil. V. I. 11 ${ }^{\text {a }}$ Ed. Editora Jus Podivm, 2009.

. Curso de Direito Processual Civil. V. II. 6ª ed. Ed. JusPodium, 2011.

DINAMARCO, Cândido Rangel. Intervenção de terceiros. cit. n. 13.

LARENZ, Karl. Metodologia da ciência do direito. 3 ed. Tradução de José Lamego. Lisboa:

Fundação Calouste Gulbenkian, 1997.

MARINONI, Luiz Guilherme. Precedentes Obrigatórios. 3 ed. São Paulo: Revista dos Tribunais, 2013.

MARINONI, Luiz Guilherme. A transformação do civil law e a oportunidade de um sistema precedentalista para o brasil. Fonte: www.marinoni.adv.br, acessado em 16.06.2011.

MARTINS, Ives Gandra da Silva. JOBIM, Eduardo. O Processo na Constituição coordenadores citados - parte: "As Reformas do Direito Processual Civil e o Princípio Constitucional da Segurança Jurídica”. Humberto Theodoro Junior. São Paulo: Editora Quartier Latin do Brasil, 2008. 
MENDES, Gilmar Ferreira. Curso de Direito Constitucional. Gilmar Ferreira Mendes, Inocêncio Mártires Coelho, Paulo Gustavo Gonet Branco. 2. ed. rev. e atual. São Paulo: Saraiva, 2008. p. 94-97.

RODRIGUES, Marcelo Abelha. Manual de Direito Processual civil. $4^{\text {a }}$ Ed. São Paulo: Editora Revista dos Tribunais, 2008, p. 450.

SANTOS, Moacyr Amaral. Primeiras Linhas de Direito Processual Civil. vol. I, 25 a Ed. ver. e atual. São Paulo: Saraiva, 2007, p. 67.

STRECK, Lenio Luiz. Súmulas no direito brasileiro: eficácia, poder e função. Porto Alegre: Livraria do Advogado, 1998.

; ABBOUD, Georges. O que é isto - o precedente judicial e as súmulas vinculantes?/ Lênio Luiz Strek, Georges Abboud - Porto Alegre: Livraria do Advogado, 2013.

SOUZA, Tiago Clemente. A nova interpretação do Direito - construção do saber jurídico/ Tiago Clemente Souza-pag.103-artigo Decisão Judicial, Hermenêutica e Segurança Jurídica: Análise sob o prisma da teoria dos Principios. E o artigo do prof. Finotti - SILVA, Nelson Finotti, disponível no site http//WWW.manualdeprocessocivil.com.br/arquivos/artigo_nelson2.pdf.) VIEIRA, Andréia Costa. CIVIL LAW E COMMON LAW. Os Dois Grandes Sistemas Legais Comparados. Porto Alegre: Sergio Antonio Fabris Editor, 2007.

WAMBIER, Teresa Arruda Alvim. Estabilidade e adaptabilidade como objetivos do direito: civil law e common law. In: Revista de Processo, São Paulo: RT, v. 172, ano 34, jun. 2009. 